\title{
EVALUATION OF CHONDROPROTECTIVE EFFICACY OF TRIAMCINOLONE IN OSTEOARTHRITIS INDUCED RAT MODEL
}

\author{
Noaman Ishaqa, Quratulain Mehdib, Novera Sohail Bajwa b, Shabana Alic, Bushra Shaheend, \\ Muhammad Waqar Aslam Khane \\ aDemonstrator, Department of Pharmacology Bakhtawar Amin Medical and Dental College, Multan. \\ bPost Graduate Trainee, Department of Pharmacology Army Medical College Rawalpindi. \\ cAssistant Professor, Department of Pharmacology Army Medical College Rawalpindi \\ ${ }^{d}$ Assistant Professor, Department of Pharmacology, Bakhtawar Amin Medical and Dental college, \\ Multan \\ eAssociate Professor, Department of Pharmacology Army Medical College Rawalpindi.
}

\section{ABSTRACT:}

BACKGROUND \& OBJECTIVE: Osteoarthritis (OA) is one of the most common joint diseases afflicting human, characterized by progressive degeneration of articular cartilage in which chondrocytes fails to repair adequately. The objective of this study isto evaluate the chondroprotection treated by triamcinolone in osteoarthritis induced rat model.

METHODOLOGY: This laboratory-based experimental study was conducted inthe Department of Pharmacology, Army Medical College, Rawalpindi, in collaboration with the National Institute of Health, Islamabad, from May-July2019. Osteoarthritis was induced by surgical removal of the medial meniscus and anterior cruciate ligament resection in the right knee joint of Sixteen (16) anesthetized rats of Sprague Dawley breed. They were divided into two (02) groups, with eight (08) rats in each group. Group-I was disease control in which $0.2 \mathrm{ml}$ Intraarticular saline was administered for three weeks. While in group-II, a treatment group was treated with $70 \mu \mathrm{l}$ intraarticular triamcinolone once weekly for three weeks. After that gait pattern of rats was scored. Animals were euthanized with overdosage of inhaled chloroform and a sample of proximal tibia was taken for histopathological analysis.

RESULTS: The mean gait score of the control group and treatment group was $3.25 \pm .707$ and $2.25 \pm .463$ with a $p$-value of 0.006 that is statistically significant. While mean histopathological modified Mankin score of the control and treatment group was $11.5 \pm 1.195$ and $8.5 \pm 1.195$, respectively, with a significant $p<0.001$.

CONCLUSION: Intraarticular administration of triamcinolone in osteoarthritis-induced rats resulted in improvement in gait pattern and histopathology.

KEYWORDS: Chondroprotective efficacy, Osteoarthritis, Triamcinolone..

\section{How to cite this:}

doi: https://doi.org/10.37723/jumdc.v12i2.463

Ishaq N, Mehdi Q, Bajwa NS, Ali S, Shaheen B, Khan MW. EVALUATION OF CHONDROPROTECTIVE EFFICACY OF TRIAMCINOLONE IN OSTEOARTHRITIS INDUCED RAT MODEL. jumdc. $2021 ; 12(2): 133-$ 139.

doi: https://doi.org/10.37723/jumdc.v12i2.463

This is an Open Access article distributed under the terms of the Creative Commons Attribution License (http://creativecommons.org/licenses/by/4.0), which permits unrestricted use, distribution, and reproduction in any medium provided the original work is properly cited. 


\section{INTRODUCTION:}

Osteoarthritis (OA) is the most common symptom of arthritis and one of the foremost causes of the persistent ailment, becoming more and more conspicuous as the person gets old.Degeneration of cartilage, the underlying bone, and the joint margin of the affected joint are characteristic of $\mathrm{OA}^{[1]}$. The joints of knee, hip, and hands are commonly affected by OA. The universal burden of this malady categorizes knee and hip OA as one of the extortionate contributors of global disability as well as disability-adjusted life years (DALYs).

$\mathrm{OA}$ is becoming more commonin aged patients as compared to past. Ratio of OA is higher in old females as compared to males. OA's risk factors are still evolving with some common factors, including old age, gender, weight, increased biomechanical loading of joints, and genetics ${ }^{[2]}$. A proper treatment of $O A$ is still not available. Non-pharmacological interventions, i.e., assistive devices (footwear and knee braces), encouraging individuals to adopt a healthy lifestyle and dietary habits to control body weight and commence moderate-intensity exercises first preferences of management of OA. Pharmacological interventions are recommended when the results of non-pharmacological interventions are unsatisfactory. Different classes of drugs are used to alleviate the severity of symptoms and delay the disease's progression. Nonsteroidal antiinflammatory drugs (NSAIDS), corticosteroids, and viscosupplement substances are widely used drug groups in OA treatment. In case of knee and hip joint $O A$ surgical interventions include arthroscopy, osteotomy and joint replacement can be an option for some individuals after the failure of pharmacological treatment ${ }^{[3,4,5]}$.

Triamcinolone is an intermediate acting synthetic glucocorticoid nature of corticosteroid, Half-life of about 18-36 hours with known anti-inflammatory and immunosuppressive properties ${ }^{[6]}$. It was introduced in the market about 50 years ago and is still used in variousdiseases. It is one of the investigational drugsis being used in the management of $\mathrm{OA}$ for decades. The Intraarticular (IA) route is the preferred route to minimize systemic exposure.

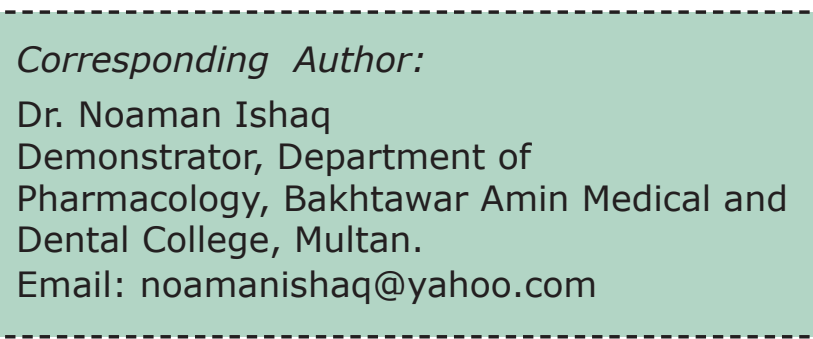

It reduces the inflammatory component of OA. OA is characterized by the presence of inflammatory mononuclear cellsand inflammatory mediators with increasedactivity of collagenases. Triamcinolone binds to intracellular glucocorticoid receptors and down-regulates the expression of genes in prostaglandins synthesis and leukotrienes release. Moreover, lipocortin expression is also enhanced that also modulates anti-inflammatory effects. These factors ultimately lessen the inflammation of the synovium and other articular structures $[7,8]$.

Furthermore, preclinical studies have shown that triamcinolone limits osteophytes development. Osteophyte development is promoted by synovial macrophage activation ${ }^{[9]}$. Triamcinolone influences macrophage activation and eventually decreases osteophytosis and cartilage degeneration ${ }^{[10]}$.

\section{METHODOLOGY:}

The design of this study was a laboratory-based experimental study. It was conducted in the Department of Pharmacology and Therapeutics, Army Medical College (AMC), Rawalpindi, in collaboration with the National Institute of Health (NIH), Islamabad, and Department of Pathology, AMC. Ethical approval of the study has endeavored from ethical review committee of "Centre for Research in Experimental and Applied Medicine (CREAM)", AMC. The duration of intervention with animals was two months, from May 2019 to July 2019. Animals wereprocured and nurtured in the animal house of NIH during the complete tenure of the study. Preliminary sixteen (16) adult male and non-pregnant female rats of Sprague Dawley breed, 08-10 weeks old and weighing about 300-400 gram, were selected through 
non-probability convenient sampling. They were randomly assigned in two (02) groups, with eight (08) rats in each group. Animals were kept in a standard environment with temperatures ranged $25 \pm 5^{\circ} \mathrm{C}$ with adequate humidity and 12 hours day-night cycle. Free excess to clean drinking water and standard rodent diet adlibitum was ensured during the whole study period.

A surgical procedure was performed to induce $\mathrm{OA}$ in the right knee joint of all rats. Before thesurgery, rats were anesthetized with an intraperitoneal injection of $5 \%$ xylazine and $1 \%$ ketamine ${ }^{[11]}$. Then the skin of the joint is shaved and disinfected, followed by a parapatellar incision on the medial side of the joint. After the complete exposure, theanterior cruciate ligament was removed and the medial meniscus was transected. The skin was closed with a surgical stapler after the completion of the surgery. After that, Animals were allowed to move freely in the cage for two weeks ${ }^{[12]}$. Then intraarticular drugs were administered in the corresponding joint of the rats. Rats of a control group and treatment groups were injected with $0.2 \mathrm{ml}$ of Normal saline and $70 \mu \mathrm{l}(1.4 \mathrm{mg} / \mathrm{ml})$ triamcinolone once weekly for 03 weeks ${ }^{[13,14]}$.

We waited for one week more before analyzing the gait score ${ }^{[15]}$.

After the gait pattern was scored, animals were euthanized with a toxic dosage of chloroform, and a sample of the proximal tibia was obtained by using the angled bone cutter. After tissue collection and histological slide preparation, these slides were scored using Modified Mankin Slide preparation $^{[16]}$. The obtained data were analyzed using SPSS version 25. Gait score and Modified Mankin score both were Quantitative parameters and compared through student t-test. The differences between the two observations were considered statistically significant if the $p$-value was equal to or less than $0.05(p \leq 0.05)$.

\section{RESULTS:}

None of the rat's surgical wounds got infected, and the animals stayed alive, healthy, and active until the end of the study. One week after the last IA injection, Gait pattern of the rats was scored by allowing them to walk the full length of $A 2$ (42x57 cm) size paper. The rats' walking pattern was observed visually with the naked eye, and the footprint made by the right injected leg was compared with the left non-injected one to analyze weight bearing throughout the movement. The gait score of three rats of the disease control group was 04, as depicted in figure-I while four and one rats of this group scored three and one, respectively. Meanwhile, theGait pattern of two rats of the triamcinolone group scored three, as depicted in figure-II while six rats of this group scored 02. The mean \pm standard deviation (SD) Gait score of a disease control group and triamcinolone group were 3.25 \pm .707 and $2.25 \pm .463$ respectively with a significant $p$-value of 0.006 when compared via Student t-test.

Histopathological analysis of all slides was done under X100 and X400 lenses. Histological changes of $\mathrm{OA}$ were scored according to the modified Mankin scoring system. A score of Slides of disease control group ranging from 1310. Figure-III is a slide of rats of this group with a 13 score. Six out of eight slides showed marked, while the rest of two showed mild irregularity in the perichondrium. One slide had marked, six had moderate, and one had mild fibrosis of perichondrium. Six slides had a moderate mark, while two slides had mild to moderate irregularity of organization. All slides showed a moderate to a marked increase in cellularity of chondrocytes. Five slides showed a moderately increased, while three slides showed mild increase in chondrocyte clusters. Five slides showed $10-20 \%$ while three slides showed $20-80 \%$ necrosis of chondrocytes. Fibrinoid degeneration was feature of all the slides of disease control group. The mean score \pm SD of group-I was $11.50 \pm 1.195$.

Slides of the triamcinolone group scored from 7-10. Figure-IV is a slide of rat of triamcinolone group. The score of this slide is 09. Seven slides of triamcinolone showed mild to moderate while one slide showed moderate to marked irregularity of perichondrium. Five slides had mild while three slides had moderate fibrosis of perichondrium. Six slides had mild to moderate while two slides had moderate to the marked irregularity of organization. Three had mild while five slides had moderate to a marked increase in cellularity and clusters of chondrocytes. Seven had $10-20 \%$ while one had $20-80 \%$ chondrocytes 
necrosis. Fibrinoid degeneration was the feature of three slides of this group. Mean score \pm SD of this group was $8.50 \pm 1.195$. When the histological score of both groups were compared with the Student t-test, we found a significant $p<0.01$. In short, we observed a visible decrease in Mean gait score and Mean Modified Mankin score of the triamcinolone group as compared to the disease group. Comparison between these two groups of gait score and histopathological score exhibited the $p<0.006$ and $p<0.001$ respectively that confirmed the chondroprotective efficacy of triamcinolone.

Table-I: Demographics and intergroup comparison of group-I (control group) and group-II (triamcinolone group).

\begin{tabular}{|c|c|c|c|}
\hline Parameter & Control group & $\begin{array}{l}\text { Triamcinolone } \\
\text { group }(n=08)\end{array}$ & p-value \\
\hline Mean \pm SD of Gait score & $3.25 \pm 0.707$ & $2.25 \pm 0.463$ & $<0.006$ \\
\hline $\begin{array}{l}\text { Mean } \pm \text { SD of modified Mankin } \\
\text { Score }\end{array}$ & $11.50 \pm 1.195$ & $8.5 \pm 1.195$ & $<0.001$ \\
\hline
\end{tabular}

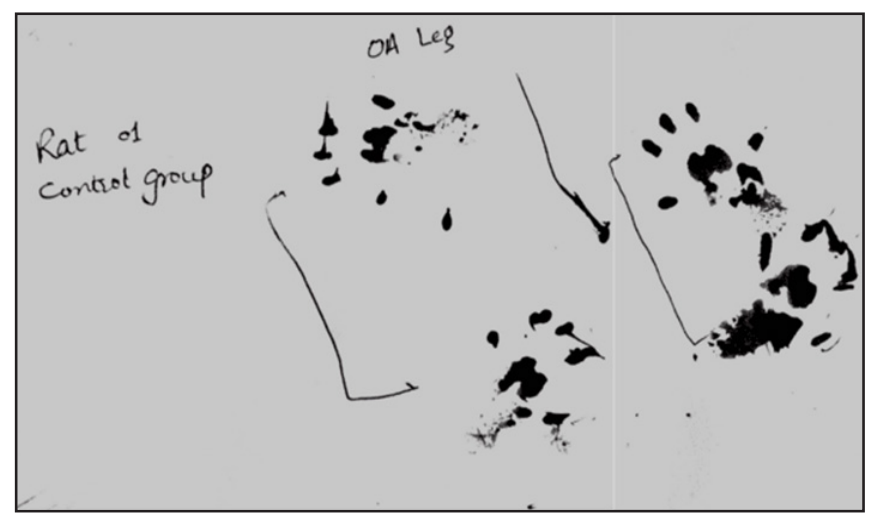

Figure-I: Gait pattern of rat of control group.

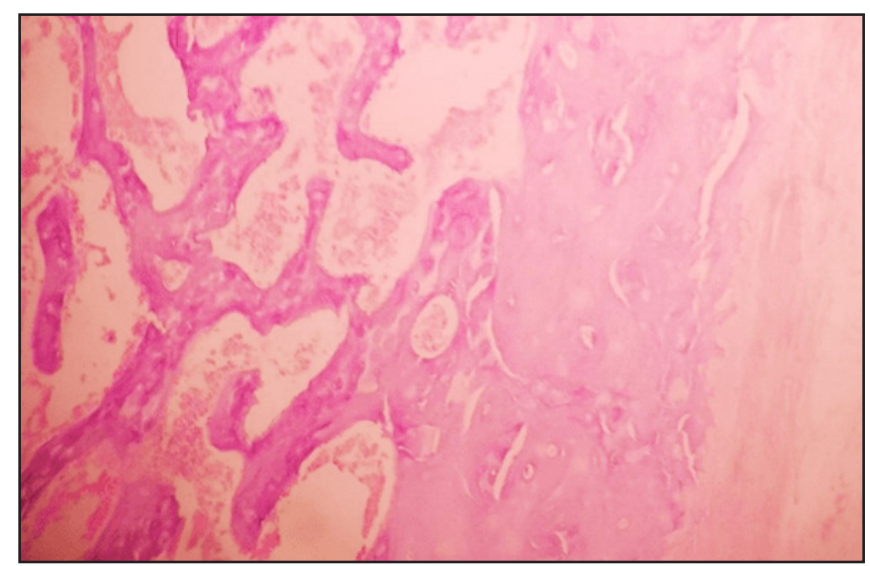

Figure-III: Photomicrograph of distal tibia of a rat of group control group.

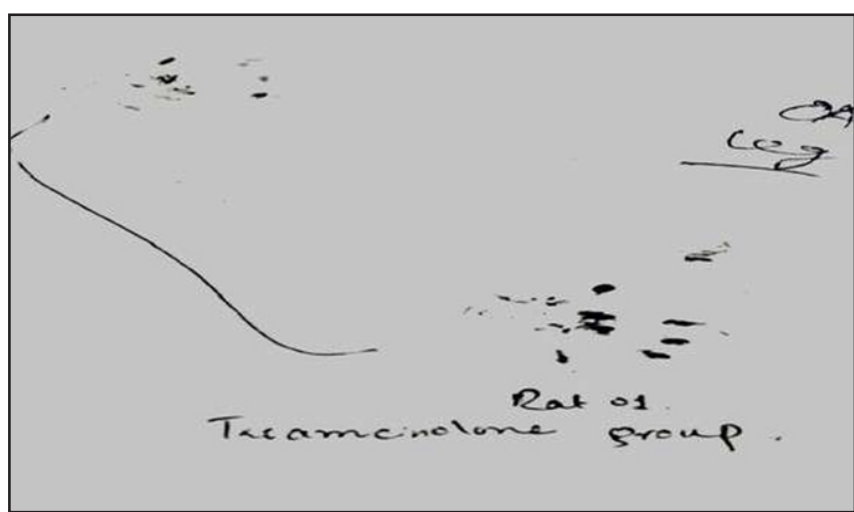

Figure-II: Gait pattern of rat of triamcinolone group

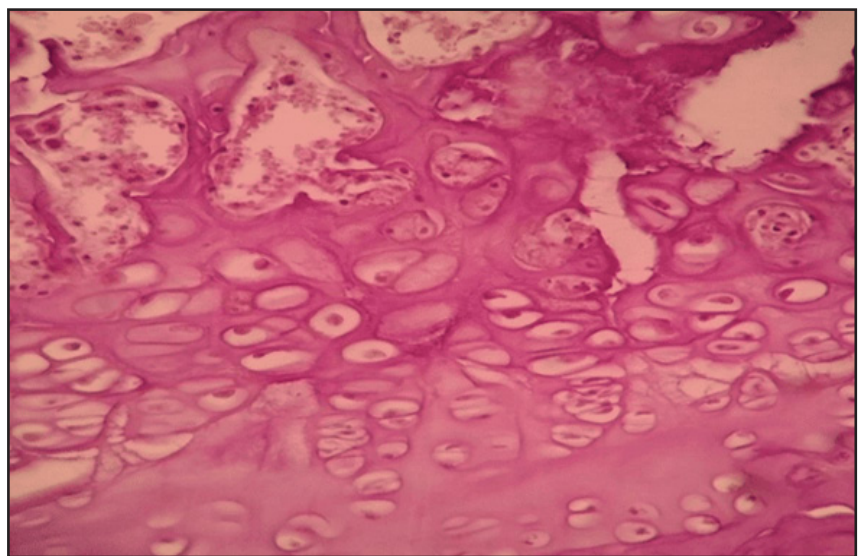

Figure-IV: Photomicrograph of distal tibia of a rat triamcinolone group. 


\section{DISCUSSION:}

$\mathrm{OA}$ is a heterogeneous degenerative joint disease with an inflammatory component. It involves the whole joint with progressive loss of hyaline cartilage, the rapid growth of bone architecture, and joint structure remodeling. It is characterized by gradual deterioration of articular cartilage with concomitant structural and functional changes in the entire joint, including capsule, synovium, ligaments, bursas, subchondral bone, and periarticular muscles ${ }^{[17]}$.

Pain and stiffness in the affected joint are hallmarks of the disease and the main cause of seeking medical advice. Common causes of pain and stiffness are increased pressure within the joint due to OA process, microfracture of trabeculum, synovitis, capsular thickness and bursitis. Pain is intermittent and insidious that gets worsened with movement and relieved by rest ${ }^{[18]}$.

Nonsteroidal anti-inflammatory drugs (NSAIDS), corticosteroids and viscosupplement substances are group of drugs that are frequently used in the management of $\mathrm{OA}^{[19]}$. Triamcinolone is a synthetic corticosteroid that is also oftenprescribed to OA patients all over the world. This animal study was designed to find the chondroprotective efficacy of triamcinolone in OA induced rat model.The dosage of triamcinolone was selected by extensive search and literature review. After the animal interventions, when gait score and modified Mankin score were compared, differences between rats of triamcinolone group and disease control group were statistically significant that confirmed the chondroprotective efficacy of triamcinolone. These results were in accordance to the 2016 research work of Jeffrey S. Kroin and fellows who claimed that triamcinolone reduces allodynia as compared to mice of a control group. Their work at the tissue culture level expressed that triamcinolone has potent anti-inflammatory effects via inhibiting expression of IL- $1 \beta$ and TNFa.

Thus it acclaimed triamcinolone chondroprotective efficacy[20]. In 2017, Yashashri C. Shetty and his colleagues did research work on chemicalinduced models of rats. Their results confirmed that triamcinolone reduces the histopathological severity of disease as compared to the disease control group ${ }^{[21]}$. In vitro study of E. Frank and fellows affirmed that triamcinolone has some chondroprotective effects on injured and inflamed cartilage via inhibiting sulfate incorporation and glycosaminoglycan loss ${ }^{[22]}$. Likewise, animal and in vitro research work of N.M Korthagen and colleagues depicted that the use of triamcinolone increases folate uptake in synovial macrophages and reduces osteophyte formation and increases cartilage thickness ${ }^{[23]}$. Similarly, Heard B] performed research work on dexamethasone, a sister drug of triamcinolone. They concluded that dexamethasone reduces the severity of OA. His research work also strengthens our results ${ }^{[24]}$. This study also has some limitations. Though the IA route of triamcinolone administration leads to less systemic exposure, we have not studied the adverse effects. Further studies should be conducted to the systemic adverse effects. Similarly, astudy similar to this contemporary study should be conducted with a prolonged duration between surgical inductions of osteoarthritis and drug administration. Delay after surgery of up to four to eight weeks may lead to more disease progression, which leads to a more severe form of the disease ${ }^{[25]}$.

\section{CONCLUSION:}

IA administration of $70 \mu \mathrm{l} \quad(1.4 \quad \mathrm{mg} / \mathrm{ml})$ triamcinolone weekly for 03 weeks reduced mean gait score and mean Modified Mankin score of histopathology compared to rats treated with IA normal saline only. Thus we concluded that triamcinolone exhibits chondroprotective efficacy in $\mathrm{OA}$ induced rat models.

ACKNOWLEDGEMENT: The authors are grateful to Dr. Hussain Ali, Scientific Officer at Animal House, National Institute of Health, Islamabad, for his guidance regarding the induction of $O A$ and administration of triamcinolone IA in rats. We owe special thanks to Army Medical College, Rawalpindi, for providing the opportunity and facilities to be carried out this research project. 
GRANTSUPPORT\&FINANCIALDISCLOSURE: We are highly obligated to the National University of Medical Sciences, Islamabad, for funding our project.

CONFLICT OF INTEREST: All authors disclose no conflict of interest

\section{REFERENCES:}

1. Fernandes MTP, Fernandes KBP, Anibal FF, Shimoya-Bittencourt W, Santos VM, De Oliveira Perrucini PD, et al. Functional status and severity of osteoarthritis in elderly is associated to the polymorphism of TNFA gene. Advances in Rheumatology. 2019;59(1):2531. Doi: $10.1186 / \mathrm{s} 42358-019-0068-6$

2. Varela-Eirin $M$, Loureiro J, Fonseca $E$, Corrochano S, Caeiro JR, Collado M, et al. Cartilage regeneration and ageing: Targeting cellular plasticity in osteoarthritis. Ageing Research Reviews. 2018;42:56-71. Doi: 10.1016/j.arr.2017.12.006.

3. Sudirman S, Ong A, Chang H-W, Kong Z-L. Effect of fucoidan on anterior cruciate ligament transection and medial meniscectomy induced osteoarthritis in high-fat diet-induced obese rats. Nutrients. 2018;10(6):686-692.

4. Bert J, Kenney J, Sgaglione NA, Mcclelland S, Brophy R, Toth J, et al. Viscosupplementation for Osteoarthritis of the Knee: A Key Opinion Leader Panel Discussion. Journal of Managed Care \& Specialty Pharmacy. 2018;24(6-a Suppl):S2-S8.

5. Holyoak DT, Tian YF, Van der Meulen MC, Singh A. Osteoarthritis: pathology, mouse models, and nanoparticle injectable systems for targeted treatment. Annals of Biomedical Engineering. 2016;44(6):2062-2075.

6. Van Heugten A, De Boer W, De Vries W, Markesteijn C, Vromans $H$. Development and validation of a stability-indicating HPLC-UV method for the determination of triamcinolone acetonide and its degradation products in an ointment formulation. Journal of Pharmaceutical and Biomedical Analysis. 2018;149:265-270.

7. McAlindon TE, LaValley MP, Harvey WF,
Price LL, Driban JB, Zhang M, et al. Effect of intra-articular triamcinolone vs saline on knee cartilage volume and pain in patients with knee osteoarthritis: a randomized clinical trial.Journal of the American Medical Association.2017;317(19):1967-1975.

8. Paik J, Duggan ST, Keam SJ. Triamcinolone Acetonide Extended-Release: A Review in Osteoarthritis Pain of the Knee. Drugs. $2019 ; 79(4): 455-462$.

9. Manferdini C, Paolella F, Gabusi E, Silvestri $Y$, Gambari L, Cattini L, et al. From osteoarthritic synovium to synovial-derived cells characterization: synovial macrophages are key effector cells. Arthritis Research \& Therapy. 2016;18(1):83-94.

10. Siebelt M, Korthagen N, Wei W, Groen $H$, Bastiaansen-Jenniskens $Y$, Müller $C$, et al. Triamcinolone acetonide activates an antiinflammatory and folate receptor-positive macrophage that prevents osteophytosis in vivo. Arthritis Research \& Therapy. 2015;17(1):352-364. Doi: 10.1186/s13075015-0865-1

11. Saadat E, Shakor N, Gholami M, Dorkoosh FA. Hyaluronic acid based micelle for articular delivery of triamcinolone, preparation, in vitro and in vivo evaluation. International Journal of Pharmaceutics. 2015;489(1-2):218-225. Doi: /10.1016/j.ijpharm.2015.05.001

12. Ozkan FU, Uzer G, Türkmen I, Yildiz Y, Senol $\mathrm{S}$, Ozkan $\mathrm{K}$, et al. Intra-articular hyaluronate, tenoxicam and vitamin $\mathrm{E}$ in a rat model of osteoarthritis: evaluation and comparison of chondroprotective efficacy. International Journal of Clinical and Experimental Medicine. 2015;8(1):1018-1026.

13. Mansour $\mathrm{HH}$, Hasan HF. Protective effect of $\mathrm{N}$-acetylcysteine on cyclophosphamideinduced cardiotoxicity in rats. Environmental Toxicology and Pharmacology. 2015; 40 ( 2 ): $417-422$. Do i : $10.1016 / \mathrm{j}$. etap.2015.07.013

14. Siebelt M, Korthagen N, Wei W, Groen $H$, Bastiaansen-Jenniskens $Y$, Müller $C$, et al. Triamcinolone acetonide activates an antiinflammatory and folate receptor-positive macrophage that prevents osteophytosis in vivo. Arthritis Research \& Therapy. 
2015;17(1):352-364.Doi: $10.1186 /$ s13075015-0865-1

15. Kumar A, Bendele AM, Blanks RC, Bodick N. Sustained efficacy of a single intra-articular dose of FX006 in a rat model of repeated localized knee arthritis. Osteoarthritis and Cartilage. 2015;23(1):151-160.Doi: 10.1016/j.joca.2014.09.019

16. Cai Z, Feng Y, Li C, Yang $K$, Sun T, Xu L, et al. Magnoflorine with hyaluronic acid gel promotes subchondral bone regeneration and attenuates cartilage degeneration in early osteoarthritis. Bone. 2018;116(1):266-278.

17. Fu K, Robbins SR, McDougall JJ. Osteoarthritis: the genesis of pain. Rheumatology. 2017;57(4):43-50.Doi: 10.1093/rheumatology/kex419

18. Zhu S, Zhu J, Zhen G, Hu Y, An S, Li Y, et al. Subchondral bone osteoclasts induce sensory innervation and osteoarthritis pain. The Journal of Clinical Investigation. 2019;129(3):1076-1093.

19. Rai SK, Raman VP, Varma R, Wani SS. Combined intra-articular injections (Hyaluronic acid, platelet-rich plasma, and corticosteroid) for osteoarthritis knee, an effective alternative treatment. Journal of Orthopedics, Traumatology, and Rehabilitation. 2018;10(1):57-60.

20. Kroin JS, Kc R, Li X, Hamilton JL, Das V, van Wijnen $\mathrm{AJ}$, et al. Intraarticular slow-release triamcinolone acetate reduces allodynia in an experimental mouse knee osteoarthritis model. Gene. 2016;591(1):1-5.

21. Shetty YC, Patil AE, Jalgaonkar SV, Rege NN, Salgaonkar S, Teltumbde PA, et al. Intraarticular injections of ketamine and $25 \%$ dextrose improve clinical and pathological outcomes in the monosodium iodoacetate model of osteoarthritis. Journal of Basic and Clinical Physiology and Pharmacology. 2017;28(6):543-553.

22. Frank $E$, Hung $H-H$, Krishnan $Y$, Senter $B$, Bodick N, Grodzinsky A. Dose-dependent chondroprotective effects of triamcinolone acetonide on inflamed and injured cartilage using an in vitro model. Osteoarthritis and Cartilage. 2019;27(1):176-184.

23. Korthagen $N$, Siebelt $M$, De Visser $H$, Sandker $M$, Müller C, Weinans $H$. Folate receptor positive macrophages in rat models for $\mathrm{OA}$ : phenotype switch in response to antiinflammatory medication. Osteoarthritis and Cartilage. 2019;27(1):373-382.Doi: 10.1016/j.joca.2019.02.365

24. Heard BJ, Barton KI, Agbojo OM, Chung M, Sevick JL, Bader TJ, et al. Molecular response of rabbit menisci to surgically induced hemarthrosis and a single intraarticular dexamethasone treatment. Journal of Orthopaedic Research. 2019;37(9):20432052.Doi: $10.1002 /$ jor. 24346

25. Bapat S, Hubbard D, Munjal A, Hunter M, Fulzele $S$. Pros and cons of mouse models for studying osteoarthritis. Clinical and Translational Medicine. 2018;7(1):36-45. Doi: 10.1186/s40169-018-0215-4.

\section{Author's Contribution:}

Noaman Ishaq: Study design, \& animal intervention.

Quratulain Mehdi: Correction and revision.

Novera Sohail Bajwa: Drafting \& editing.

Shabana Ali: Data analysis, result compilation. Bushra Shaheen: Biostatistics, data analysis.

Muhammad Waqar Aslam Khan:

Biostatistics, result compilation.

Submitted for Publication: 18-08-2020

Accepted after revision: 05-04-2021 